\title{
Common malignant cutaneous conditions among albinos in Kenya
}

\author{
Seyed Emad Emadi ${ }^{1}$, Andrew Juma Suleh ${ }^{2}$, Farhang Babamahmoodi ${ }^{3}$, Fatemeh Ahangarkani ${ }^{4}$, \\ Vanessa Betty Chelimo ${ }^{2}$, Beatrice Mutai ${ }^{2}$, Seyyed Reza Raeeskarami ${ }^{5}$, Alireza Ghanadan ${ }^{6}$, Seyed Naser Emadi ${ }^{*}$
}

\begin{abstract}
Background: Albinos in Africa are at constant risk of developing skin cancer due to the damage caused by ultra-violet exposure. This study identifies the common skin conditions among albinos in Kenya as a country located along the equator.

Methods: In this descriptive study on albino patients who were admitted to Mbagathi District Hospital in Nairobi, Kenya the census method was used for sampling and a total of 151 albinos were registered. All necessary data including age, gender, type, site and the number of skin lesions were recorded. Suspected patients with malignant and premalignant lesions were studied individually through skin biopsy and histopathological investigation. Finally, the collected data were analyzed using SPSS software.

Results: Albinos with serious skin lesions were 121(80\%) patients. Females were $64(52.9 \%)$. The frequency of the following premalignant and malignant skin lesions including actinic-cheilitis, solar elastosis, actinic keratosis (AK), basal cell carcinoma (BCC) and squamous cell carcinoma (SCC) were $17.88 \%, 11.92 \%, 37.08 \%, 7.94 \%$ and $5.29 \%$, respectively. Hands $(20.52 \%)$, face $(19.20 \%)$, head (18.18\%), shoulder (14.56\%) and neck (7.94\%) were the most affected areas by malignant and premalignant lesions.

Conclusions: BCC was the most common type of cutaneous malignancy on the face and shoulders while AK was the most common cutaneous pre-malignancy on the hands and face in albinos in Kenya. Therefore, appropriate physical protection, avoiding any trauma when carrying sharp, heavy or rough instruments by the shoulder and hands, and finally urgent and quality treatment for any lesion even a small erosion and ulcer, especially on exposed areas in albinos, are recommended.
\end{abstract}

Keywords: Albinos, Skin Cancer, Kenya

Copyright $@$ Iran University of Medical Sciences

Cite this article as: Emadi SE, Juma Suleh A, Babamahmoodi F, Ahangarkani F, Betty Chelimo V, Mutai B, Raeeskarami SR, et al. Common malignant cutaneous conditions among albinos in Kenya. Med J Islam Repub Iran. 2017(12 Jan);31:3. https://doi.org/10.18869/mjiri.31.3

\section{Introduction}

Albinism is an inherited disorder characterized by the complete or partial absence of pigment melanin in the skin, hair and eyes due to absence or defect of tyrosinase, an enzyme involved in the production of melanin $(1,2)$. Albinism has a worldwide distribution; it affects only 1 in 20,000 people. In Africa, incidences ranging from 1 in 2,700 to 1 in 10,000 have been reported in different studies $(3,4)$. Melanin as a photo protective pigment protects the skin from the effects of ultraviolet radiation (3). Persons with albinism and other skin diseases such as vitiligo,

\section{Corresponding author: Dr Seyed Naser Emadi, sne.tums@gmail.com}

1. Mazandaran University of Medical Sciences, Sari, \& Iranian Red Crescent Society, Tehran, Iran

2. Mbagathi District Hospital, University of Nairobi, Nairobi, Kenya

3. Antimicrobial resistance research center, Mazandaran University of Medical Sciences, Sari, Iran

4. Antimicrobial Resistance Research Center, Student Research Committee, Mazandaran University of Medical Sciences, Sari, Iran

5. Department of Pediatric, Imam Khomeini hospital, Tehran University of Medical Sciences, Tehran, Iran \& Iranian Red Crescent Society, Tehran, Iran

6. Department of Dermatopathology, Razi hospital, Tehran University of Medical Sciences, Tehran, Iran

7. Skin Research Center, Razi Hospital, Tehran University of Medical Sciences, Tehran, Iran \& Iranian Red Crescent Society, Tehran, Iran psoriasis, lichen planus and Darier diseases are at constant risk of developing skin cancer due to the damage caused by ultra-violet exposure and, African albinos are at more risk of developing skin cancers given their location along the equator (5-7). The lack of melanin in African albinos increases the risk of developing skin cancer by 1,000 fold as compared with the general African population $(8,9)$. The three most common forms of skin cancer are BCC, SCC and melanoma. Skin cancer usually occurs on the scalp, ears, back of the hands, or the lower lip.

$\uparrow$ What is "already known" in this topic:

In Africa, albinism incidence ranges from 1 in 2,700 to 1 in 10,000 in different regions. Kenyan albinos who live on the equator line are at constant risk of developing skin cancer due to the damage caused by ultra-violet exposure.

$\rightarrow$ What this article adds:

Actinic keratosis still remains as the predominant skin condition found among Kenyan people living with albinism. Concerning the skin cancer, sensitization and informing the albino patients, especially outdoor workers, might decline the number of patients with $\mathrm{AK}, \mathrm{SCC}$, and $\mathrm{BCC}$. 


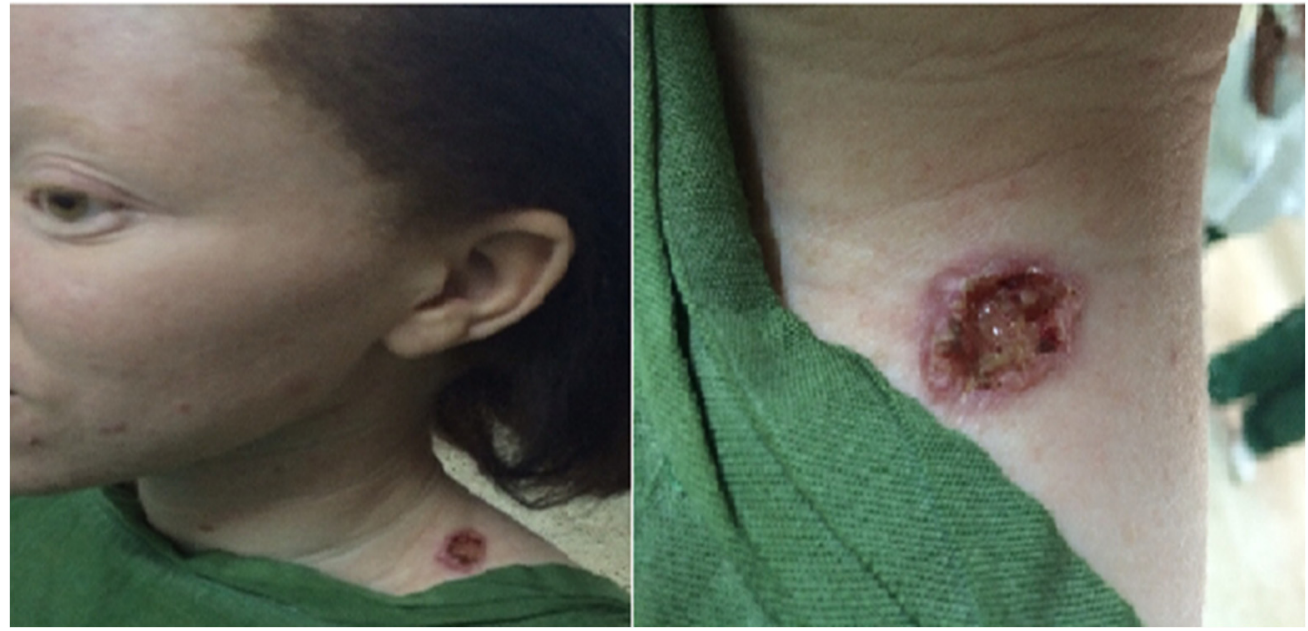

Fig. 1. BCC lesion on patient's shoulder

On the other hand, one of the major problems for albinos particularly in east Africa, is that they are persecuted for different superstitious reasons such as believing that certain body parts of albinistic people can transmit magical powers or will bring prosperity to the user (muti or medicine murder)(10) As a result, in fear of being persecuted, killed or dismembered, albinos with skin conditions, even metastatic form of skin cancer, would prefer to stay at home forever instead of appearing in public, and do not even go for medical checkup which might result in their death. Therefore, one of the marginal aims of this work was notifying and motivating humanitarian medical groups to put all their effort in saving albino patients. Besides, no data on albinism were available for Kenya, a country that is situated in the African great lakes region of east Africa and is located on the equator and, is exposed to high-intensity ultraviolet light which might cause more cases of severe skin disorders, particularly among unprotected Albino patients. This study is the first of its kind to assess the skin conditions of albino patients in Kenya and might be considered as a fundamental study for future studies. This paper presents data from a survey on albino patients and their skin conditions in Nairobi, the capital and the largest city of Kenya.

The main purpose of this work is to find out, according to age, gender, and location of lesion, what kind of premalignant and malignant cutaneous lesions could be found among Kenyan Albino patients admitted to Mbagathi District Hospital (MDH), and also what kind of humanitarian work and public announcements could be considered to save the life of albinos in the future.

\section{Methods}

This is a prospective study covering a period of 2 years (from August 2012 to August 2014) on albino patients referred to MDH, Nairobi, Kenya. MDH is one of the main government hospitals in Kenya. The first albino clinic in Kenya (MDH) was established with the name of IMAM HUSSAIN (a.s) albino skin clinic, in 2012 according to joint research activities between University of Nairobi (UON), Kenya, Iranian Red Crescent Society and Tehran University of Medical Sciences (TUMS), Iran. The main mission of this clinic is medical and psychosocial services as well as gathering information on all albino patients for better medical and social support in the future. Albino patients were noticed and guided to this clinic by Albino Foundation of East Africa (AFEA) and other possible and accessible public announcements.

All the albino patients referred were included in the project (census method) after obtaining written consent from. All necessary data including age, gender, type, site and the number of skin lesions were recorded. Suspected patients with malignant and premalignant lesions were studied individually through skin biopsy and histological investigation. As an example, an 18-year-old girl had a tumor on her shoulder which is shown in (Fig. 1), histopathological findings revealed that the tumor is $\mathrm{BCC}$ with microscopic description of a solid tumor composed of basaloid keratinocytes arranged in nests and strands embedded in a fibro mucinous stroma which is shown in (Fig. 2).

Descriptive statistics and frequency distribution (n, \%) were reported using the SPSS v.16.

\section{Results}

Out of 151 albinos that were referred to MDH, 121 $(80 \%)$ patients with serious skin lesions were identified,

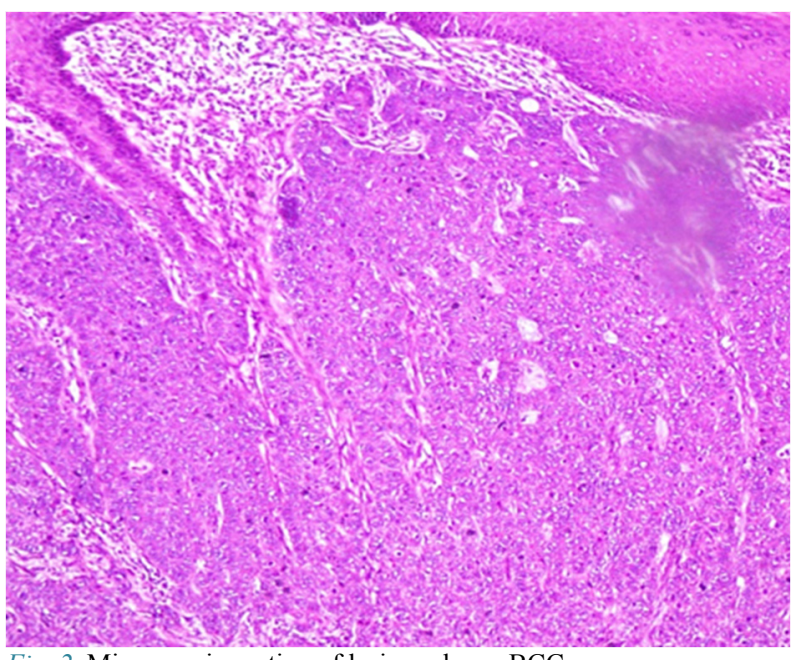

Fig. 2. Microscopic section of lesions shows BCC. 
64 of them $(42.38 \%)$ were female, and $57(37.74 \%)$ were male. The most frequent age group was 21 - 30 years old (Fig. 3). Premalignant (actinic keratosis) and solar skin lesions (actinic cheilitis and solar elastosis) were found in $57(37.74 \%)$ females and $44(29.13 \%)$ males. AK was seen in 56 cases while 30 of them were females. Distribution of patients according to types of lesions and sex is illustrated in (Fig. 4).

In a few albinos, different types of pre and malignant lesions were discovered in more than one location. For example, in a 38-year-old woman, in addition to $\mathrm{AK}$ on her hands and face, another two lesions of BCC were seen on her face and head.

Malignant lesions including $\mathrm{BCC}$ and $\mathrm{SCC}$ were discovered in $12(7.94 \%)$ and $8(5.29 \%)$ albinos patients. Sites and types of lesions for premalignant and malignant lesions are shown in (figure 5). 31 cases $(20.52 \%)$ had AK on their hands which was the most common site for premalignant lesion and then face, head, shoulders, and neck with 21(13.9\%), 16(10.59\%), 7 (4.63\%) and $11(7.28 \%)$ respectively were other common sites of lesions.

\section{Discussion}

The main aim of this study was to concentrate on the situation of skin cancer among Kenyan's albinos according to age, sex, type, and location of malignancies which had not been reported. High levels of exposure to ultraviolet radiation increase the rate of skin cancer in albinos. The ultraviolet dose per unit time at the equator is about $200 \%$ of that in the northern USA or Europe. The hot weather conditions and the farming activities in this community limit the use of quality sun-protective clothing, and this fact itself may increase the rate of skin cancer (2, 11). Also skin cancers are a major cause of morbidity among albinos in the tropics (3). Skin cancers are generally among the middle-aged and elderly, but in albinos, these cancers present themselves earlier (12). Most skin cancers in African albinos occur after the age of 20(13). All the given predisposing factors, including the geographic location of Kenya (being in the equator), personal behaviors (such as not protecting themselves against the sun) and social behaviors of Kenyans (not having enough education on the matter and lack of social services) were seen in our study.

The rates of patients of this study were $13.24 \%$ (20 cases) for cutaneous malignancies and $54.96 \%$ (83cases) for cutaneous pre-malignancies (AK and $\mathrm{AC}$ ). The rate of incidence of skin cancer in albinos in our study is close to Mabula et al's findings (14).

The converse of our findings is the rate of skin cancer in Kromberg et al's study which was $23.4 \%$ (15). In our study, the majority of patients were aged between $21-30$ years old (37.74\%) which is almost similar to a study conducted in northern Tanzania. On the other hand, similar to what we found in this work, Kiprono et al. reported that the most of the albinos with skin cancer were below 40 years $(2,16)$. Therefore, the fact that most cases enrolled in our study were in either of the two groups (below 10 and 21-30 years old) could be due to the responsibility and

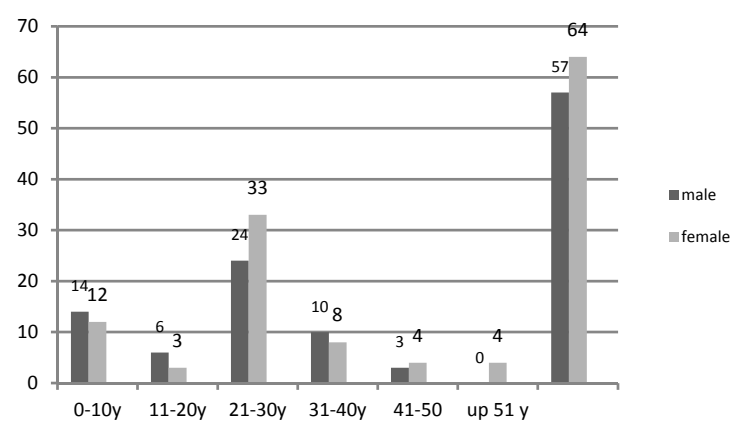

Fig. 3. Rate of albinos with serious skin lesions by age group distribution and sex

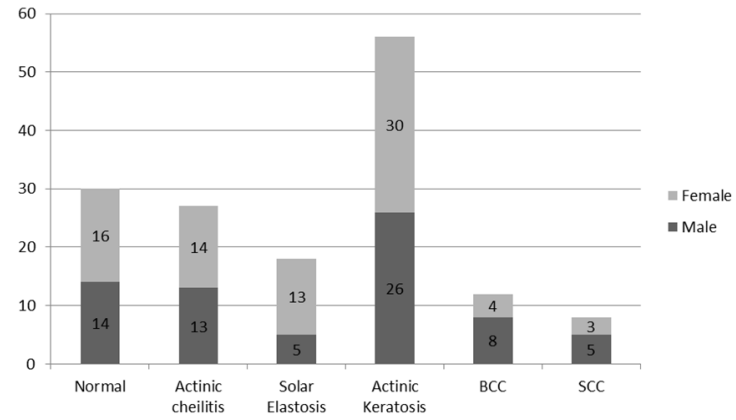

Fig. 4. Distribution of all albinos according to the types of lesions and sex

special care of parents to their albino kids that were below the age of 10 and, full attention of 21-30-year olds, especially women to their appearances and their skin condition. In this work premalignant lesions (actinic cheilitis and actinic keratosis) were found more in females (44 cases) than in males (39 cases). Unlike skin cancer in male patients (13 cases) that were more than female patients (7 cases). This means the nature and structure of skin in females are in a way that when exposed to sunlight has more potential of developing skin illness compared to men. But full attention of women to their skin condition, even just a small and new lesion, could be one of the main reasons that they prevent pre-malignant lesions from developing into malignant lesions more than men that don't usually care as much.

In a 10-year retrospective review of the histology of skin cancers in Africa, Kiporna did not see any gender differences (2). Whereas Asuquo et al. and Yakubu et al. reported that male patients were more affected than females $(17,18)$. On the other hand, the large number of visits of females shows that there is more self-attention in this gender and therefore the low incidence of skin cancer in females could be compatible with our findings in Kenya. In this study, the most found type of pre-malignancies was AK (45.04\%) on hands, face and neck. Prevalence of AK depends upon the skin type, geographical location and duration of exposure to sunlight which without treatment might develop into SCC as Kiporno observed in his study and stated that SCC was more common than BCC in African albinos. (2)

Unlike above, our findings in this study explained that 
BCC was more common than SCC in albinos in Kenya, which is in conflict with Kiporno's. To respond to this conflict, the rate of development of SCC from AK is almost 0.025 to $16 \%$. (19). In addition, there is no correlation between AK and BCC. Therefore, we can claim that the current simple and available treatment (cryotherapy) can cure $\mathrm{AK}$ before it develops into SCC malignant lesion. But since the source of $\mathrm{BCC}$ is not any premalignant lesion or $\mathrm{AK}$ as it is for SCC, its early treatment is difficult $(20,21)$.

About the locations of BCC, face and shoulders were the most common affected areas in our study, compared to head and neck in Ferreira et al. and Asuquo et al. studies (22-24).

To prove this difference, we would like to express this hypothesis that injured shoulder, particularly among outdoor workers could be one of the main possible causes of developing BCC, as we saw a number of albinos in our study with erosions and ulcers on their shoulders because of carrying heavy metallic and wooden objects. Opera et al. reported that SCC was the most found skin cancer in albinos in a teaching hospital in eastern Nigeria and the head and neck region was the commonest site of lesions (3). Head was the most affected location by SCC in our study which is similar to many other reports $(3,16,17,25)$.

\section{Conclusion}

AK still remains as the predominant skin condition found among people living with albinism. It seems that early and rapid treatment of AK in our study prevented the growth of SCC cancer more than other studies. Concerning the skin cancer, sensitization and informing the albino patients, especially outdoor workers, might decline the number of patients with AK, SCC, and BCC. Finally, any lesion must be more attended to early and rapid treatment, especially on the dorsal of hands and shoulders that are at the risk of trauma because of carrying rough materials and being in contact with chemical substances and sun exposure.

\section{Acknowledgement}

The authors of this study have the utmost gratitude to Professor Alireza Firuz for the revision of this article.

Conflict of Interest: The authors declare that they have no competing interests.

\section{References}

1. Hong ES, Zeeb H, Repacholi MH. Albinism in Africa as a public health issue. BMC Pub Health. 2006; 6: 212.

2. Kiprono SK, Chaula BM, Beltraminelli H. Histological review of skin cancers in African Albinos: a 10-year retrospective review. BMC Cancer. 2014; 14(157): 1471-2407.

3. Opara KO, Jiburum BC. Skin cancers in albinos in a teaching Hospital in eastern Nigeria - presentation and challenges of care. World J Surg Oncol. 2010; 8: 73.

4. Shapiro MP, Keen P, Cohen L, Murray JF. Skin cancer in the South African Bantu. Br J Cancer. 1953; 7(1): 45-57.

5. Kagore F, Lund PM. Oculocutaneous albinism among schoolchildren in Harare, Zimbabwe. $J$ Med Genet. 1995;32(11): 859-861.

6. Emadi SN, Akhavan-Mogaddam J, Yousefi M, Sobhani B, Moshkforoush A, Emadi SE. Extensive hypertrophic lichen planus in an HIV positive patient. Dermatol Online J. 2010;16(6): 8 .

7. Emadi SN, Izadi M, Poursaleh Z, Akhavan-Moghaddam J, Barikbin B, Emadi SE. Darier disease associated with HIV infection: a case report. HIV Clin Trials 2011;12(1): 48-53.

8. Higgenson, J. Malignant neoplastic disease in the south African Bantct. Cancer 1951;4(6): 1224-1231.

9. Cruz-Inigo AE. Ladizinski B. Sethi A. Albinism in Africa: stigma, slaughter and awareness campaigns. Dermatol Clin. 2011; 29(1): 79-87.

10. Schuhle, J. "Medicine murder of people with albinism in Tanzania How casino capitalism creates rumorscapes and occult economies." CAS (Center for Area Studies) Working Papers Series no. 2. Berlin: Center for Area Studies, Freie Universit at Berlin, 2013.

11. Fears TR, Scotto J. Estimating increases in skin cancer morbidity due to increases in ultraviolet radiation exposure. Cancer Invest. 1983; 1(2): 119-26.

12. Alexander GA, Henschke UK. Advanced skin cancer in Tanzanian albinos: preliminary observations. J Natl Med Assoc. 1981; 73(11): 1047-54.

13. Okoro AN. Albinism in Nigeria. A clinical and social study. Br J Dermatol. 1975; 92(5): 485-92.

14. Mabula JB, Chalya PL, Mchembe MD, Jaka H, Giiti G, Rambau P, et al. Skin cancers among Albinos at a University teaching hospital in Northwestern Tanzania: a retrospective review of 64 cases. BMC Dermatol. 2012;12: 5.

15. Kromberg JG, Castle D, Zwane EM, Jenkins T. Albinism and skin cancer in Southern Africa. Clin Gen. 1989; 36(1): 4352 .

16. Luande J, Henschke CI, Mohammed N. The Tanzanian human albino skin. Natural history. Cancer. 1985; 55(8): 1823 8.

17. Yakubu A, Mabogunje OA. Skin cancer in African albinos. Acta Oncologica. (Stockholm, Sweden) 1993; 32(6): 621-2.

18. Asuquo ME, Otei OO, Omotoso J, Bassey EE. Letter: Skin cancer in albinos at the University of Calabar Teaching Hospital, Calabar, Nigeria. Dermatol Online J. 2010;16(4): 14.

19. Agale SV, D'Costa GF, Bharambe BM, Bhatia V. Childhood actinic keratosis in an albino transforming into squamous cell carcinoma. Indian Dermatol Online J. 2012; 3(3): 199-201.

20. Emadi SN, Hosseini-Khalili A, Soroush M, Ardakani MK, Ghassemi-Broumand M, Davoodi SM, Amirani O, Haines D. External urethral stenosis: A latent effect of sulfur mustard two decades' post-exposure. Intl Jo Dermatol. 2009;48(9): 960963.

21. Emadi SN, Babamahmoodi F, Poursaleh Z, Sayad-Noori SS, Soroush MR, Maleki AR, Izadi M, Khodaei-Ardakan MR, Emadi SE. Sézary syndrome, kaposi sarcoma and generalized dermato-phytosis 15 years after sulfur mustard gas exposure. J Dermatol Case Reports. 2012; 6(3): 86-89.

22. Ferreira FR, Pevide BD, Rodrigues RF, Nascimento LF, Lira ML. Differences in age and topographic distribution of the different histological subtypes of basal cell carcinoma, Taubate (SP), Brazil. Anais Brasil Dermatol. 2013; 88(5): 72630

23. Asuquo ME, Agweye P, Ugare G, Ebughe G. Basal cell carcinoma in five albino Africans from the south-eastern equatorial rain forest of Nigeria. Intl J Dermatol. 2007; 46(7): 754-6.

24. Emadi SN, Aslani J, Poursaleh Z, Izadi M, Soroush M, Kafashi M, Alavinia SA, Bakhshi H, Karimi A, Momtaz- 
Manesh K, Babaei AA. Comparison late cutaneous complications between exposure to sulfur mustard and nerve agents. Cutan Ocul Toxicol. 2012; 31(3): 214-219.

25. Kromberg JG, Castle D, Zwane EM, Jenkins T. Albinism and skin cancer in Southern Africa. Clin Genet 1989; 36(1): 43. 